\title{
Fluoride Release from Glass lonomer Cements: Effect of Temperature, Time Interval and Storage Condition
}

\author{
Prashanthi Madhyastha, Ravindra Kotian, Vivekananda Pai, AMA Khader
}

\begin{abstract}
Objectives: Fluoride plays a pivotal role in oral health promotion and is the corner stone in the prevention of dental caries. The purpose of this study was to evaluate the effects of temperature, time interval and storage conditions on fluoride release by three commercial glass ionomer cements (GIC).
\end{abstract}

Materials and methods: Three commercial glass ionomers: GC Gold Label Universal Restorative (conventional), GC Gold Label Light-Cured Universal Restorative and GC Fuji VII (GC Corporation, Tokyo, Japan) were used to investigate fluoride release. The $6 \times 2 \mathrm{~mm}$ disk-shaped specimens prepared from each material were immersed in distilled water or artificial saliva at temperatures $4^{\circ} \mathrm{C}, 37^{\circ} \mathrm{C}$ or $55^{\circ} \mathrm{C}$. The amount of fluoride release from these specimens was studied for the period of 1,7 , 14 and 28 days with the help of fluoride selective ion electrode.

Results: The amount of fluoride release was significantly $(p<0.001)$ high in distilled water when compared to artificial saliva in all the three types of GIC studied. The highest level of fluoride release was observed on the first day of the study, followed by days 7 and 14, with least release on days 28 . It was also observed that at $55^{\circ} \mathrm{C}$, the amount of fluoride release was significantly $(p<0.001)$ high in all three GIC. However, there was no significant difference among the three GIC studied.

Conclusion: The amount of fluoride release depends on temperature, time interval and storage condition. The result from the study concludes that GIC in the oral cavity serve as fluoride reservoir and contribute a low fluoride release in oral fluids.

Clinical significance: The clinical use of GIC that release fluoride is relevant mainly in patients at risk of or with caries activity, thereby preventing initiation of secondary caries and failure of restorations. It may also be important in developing regimes for improving the delivery of tropical fluoride products. This study would be helpful to make some considerations about clinical indication and longevity of restorative materials studied.

Keywords: Glass ionomer cement, Fluoride release, Fluoride selective electrode.

How to cite this article: Madhyastha P, Kotian R, Pai V, Khader AMA. Fluoride Release from Glass Ionomer Cements: Effect of Temperature, Time Interval and Storage Condition. J Contemp Dent 2013;3(2):68-73.

Source of support: Nil

Conflict of interest: None declared

\section{INTRODUCTION}

Secondary caries leading to failure of restorations remain the most inevitable problem in restorative dentistry. ${ }^{1-3}$ Fluoride plays a pivotal role in oral health promotion and is the corner stone in prevention of dental caries, both in children and adults. ${ }^{4-6}$ Restorative materials when placed in oral cavity can serve as fluoride reservoir and contribute to low fluoride release in oral fluids thereby preventing dental caries. ${ }^{1,7-9}$ Release of fluoride ions from the restorative materials could be a substantial benefit because fluoride can enrich neighboring enamel or dentine to combat caries. The fluoride release from restorative materials in deionized water has been the subject of many studies ${ }^{10-13}$ but the behavior of these materials under conditions of varying temperature and time that simulates the conditions of oral cavity, needs to be further explored. Thus, estimation of fluoride release from glass ionomer cement (GIC) under varying conditions of temperature, time and storage that simulates the conditions of oral cavity becomes important. Therefore, the study aims to evaluate the effects of temperature, time interval and storage conditions on the fluoride release by three commercial GIC. The hypothesis to be tested includes that fluoride release from GIC is affected by temperature, time and storage conditions.

\section{MATERIALS AND METHODS}

Three commercial glass ionomers: GC Gold Label Universal Restorative (Conventional), GC Gold Label Light-Cured Universal Restorative and GC Fuji VII (GC Corporation, Tokyo, Japan) were used to investigate fluoride release.

Specimen preparation: All specimen preparation was done by a single operator, in order to reduce variability. Specimens were prepared using teflon molds $(6 \mathrm{~mm}$ diameter $\times 2 \mathrm{~mm}$ thickness). The mold were sandwiched between transparent matrix strip and glass slide. The uncured composites were inserted into the mold until it was intentionally overfilled. Light pressure was applied to expel excess material from the mold. For GC light cured and GC Fuji VII, each specimen was light cured through the top and bottom glass slide for the duration recommended by the manufacturers. For GC conventional, the material were left in the mold for self cure. The set cylindrical specimen was separated from the mold. The specimens were stored at $100 \%$ relative humidity at $37^{\circ} \mathrm{C}$ for 24 hours.

\section{Experimental design (Flow Chart 1):}

Thirty-six specimens for each GIC to be tested were fabricated. Eighteen specimens each were immersed in one of the two groups: $20 \mathrm{ml}$ of distilled water or artificial saliva in $30 \mathrm{ml}$ test tube. Specimen were further subdivided into 
three groups $(\mathrm{n}=6)$ to be stored at $4^{\circ} \mathrm{C}$ (in refrigerator) Figure $1,37^{\circ} \mathrm{C}$ (in an incubator), Figure $2,55^{\circ} \mathrm{C}$ (in a water bath), Figure 3 for 1 day. At the end of 24 hours the

Flow Chart 1: Experimental design
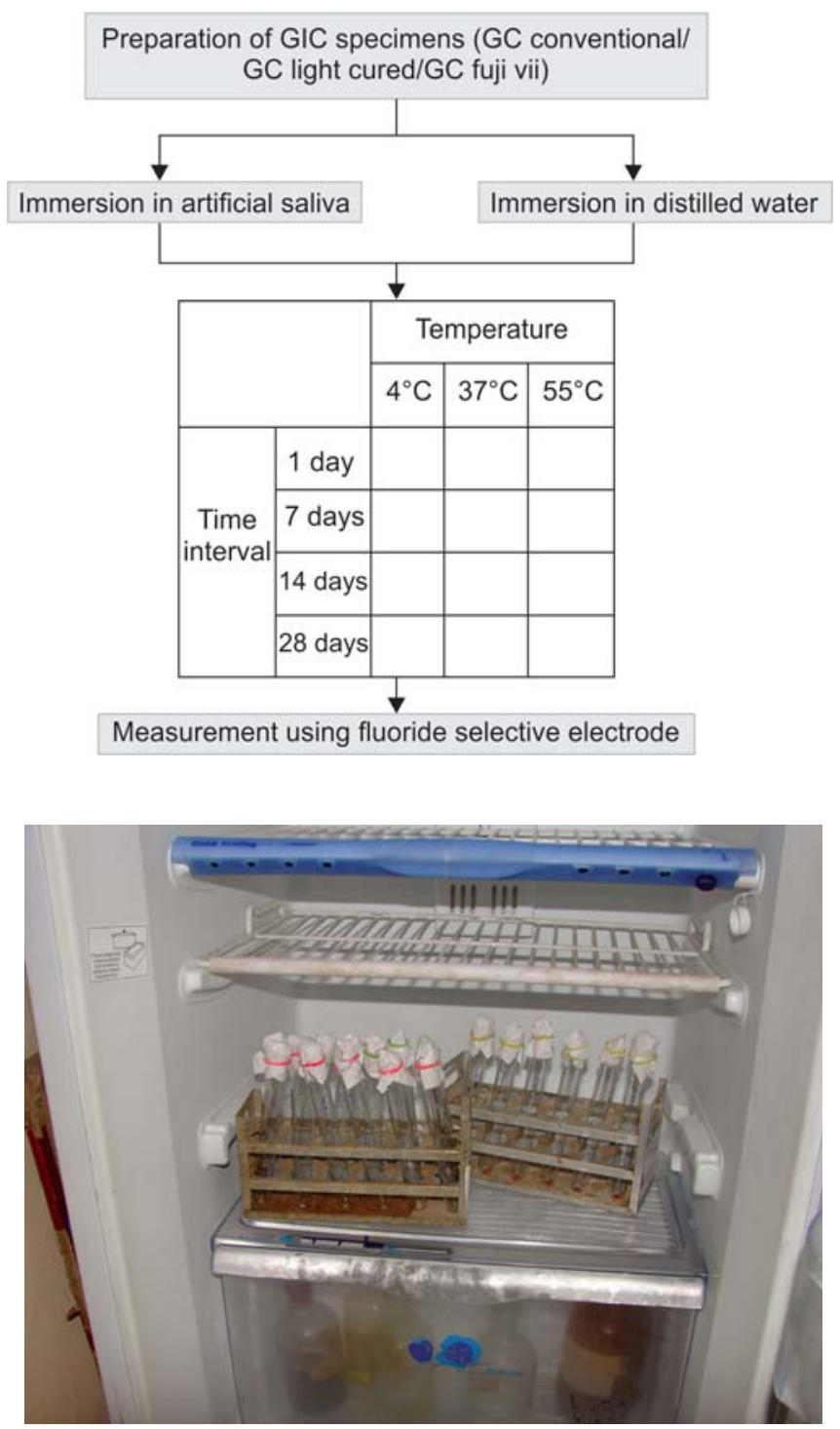

Fig. 1: Specimens in fridge

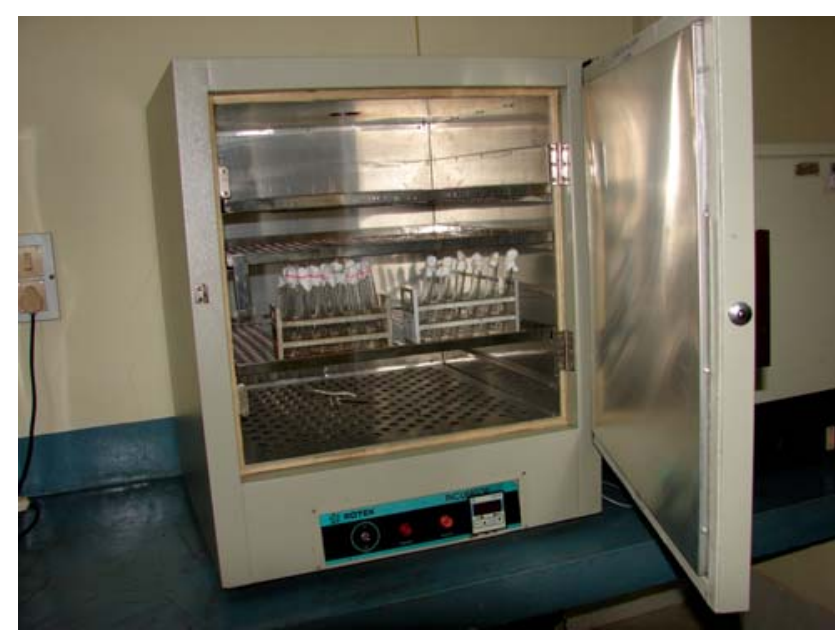

Fig. 2: Specimens in incubator specimens were removed, washed with distilled water and dried with blotting paper, before being transferred to a fresh plastic container containing $20 \mathrm{ml}$ of distilled water or artificial saliva. Sterile plastic containers were used throughout as glass vessels which are known to absorb and leach fluoride. ${ }^{14}$ Solution at the end of 1 day, 7-day, 14-day, and 28-day time interval were collected and fluoride release were measured using a fluoride sensitive electrode [pH/Ion 510, Oakton (CE), Eutech Instruments Pte Ltd, USA] (Fig. 4) by adding 1:1 quantity of total ionic strength adjustment buffer (TISAB) solution. The electrode was standardized on the day of analysis with a range of fluoride standards $(0.1,1.0,10 \mathrm{ppm})$ diluted with TISAB. A calibration curve was produced with the values of the known standards from which the values of the test samples were calculated. For each sample, analysis was done three times and mean was taken to obtain accurate results.

Statistical analysis: The data are expressed as mean \pm SD. The significance of differences among the groups are assessed using one-way analysis of variance (ANOVA) test

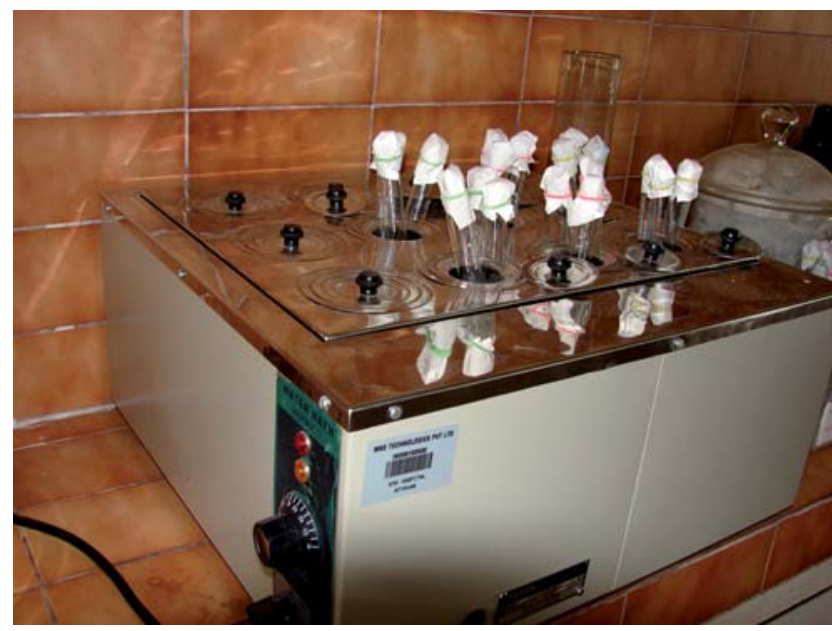

Fig. 3: Specimens in waterbath

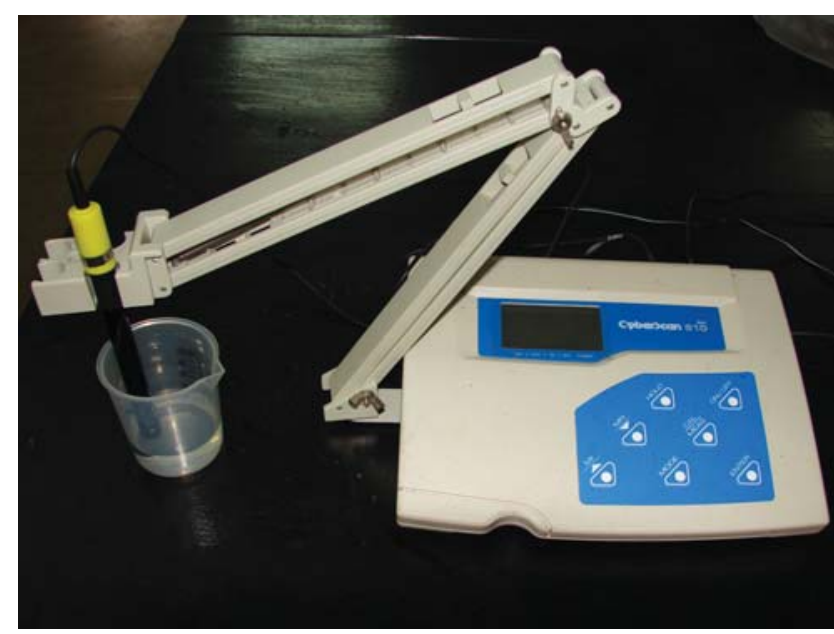

Fig. 4: Fluoride sensitive electrode 
followed by Bonferroni's multiple comparison test (unmatched groups). p-values $<0.05$ are considered as significant. Comparison of data between artificial saliva and distilled water is assessed by Mann-Whitney's unpaired ' $\mathrm{t}$ ' test (unpaired groups).

\section{RESULTS}

The effect of temperature as well as time interval has not shown any significant difference in fluoride releasing ability in all the three GIC (irrespective of saliva or distilled water). Hence, further analyses of results are generalized for all the three GIC studied.

Effect of temperature on fluoride release in distilled water (Graph 1 and Table 1): It has been observed that, the maximum fluoride release was in $55^{\circ} \mathrm{C}$ followed by $37^{\circ} \mathrm{C}$ and $4^{\circ} \mathrm{C}$ temperature. Statistically, there was a significant difference $(\mathrm{p}<0.01)$ between $4^{\circ} \mathrm{C}$ and $55^{\circ} \mathrm{C}$ temperature and also between $37^{\circ} \mathrm{C}$ and $4^{\circ} \mathrm{C}(\mathrm{p}<0.05)$ after 28 days of immersion. However, there was no significant difference between $37^{\circ} \mathrm{C}$ and $55^{\circ} \mathrm{C}$ for 28 days study $(\mathrm{F}=10.207)$. For 14 days of study, there was a significant difference $(\mathrm{p}<$ 0.01 ) between $37^{\circ} \mathrm{C}$ and $55^{\circ} \mathrm{C}$ temperature $(\mathrm{F}=6.770)$. There

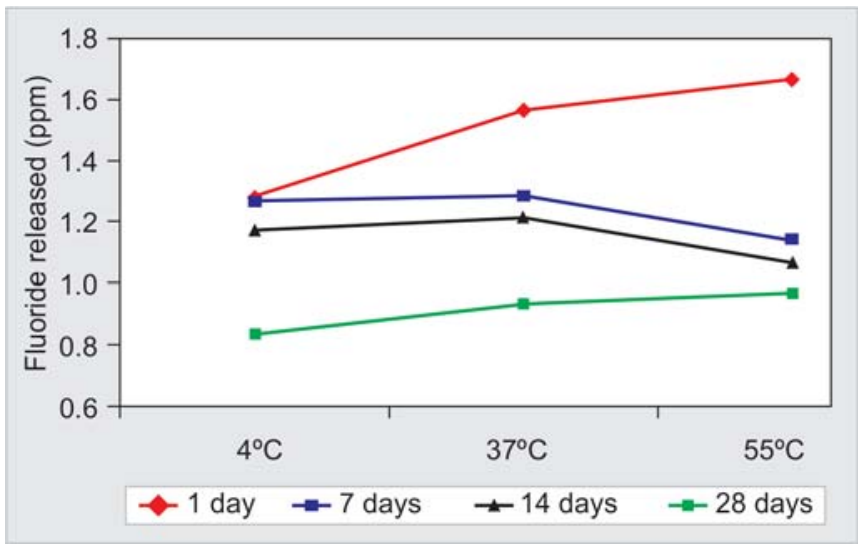

Graph 1: Effect of temperature on fluoride release in distilled water. Values are expressed as mean ppm (parts per million) $(n=6)$

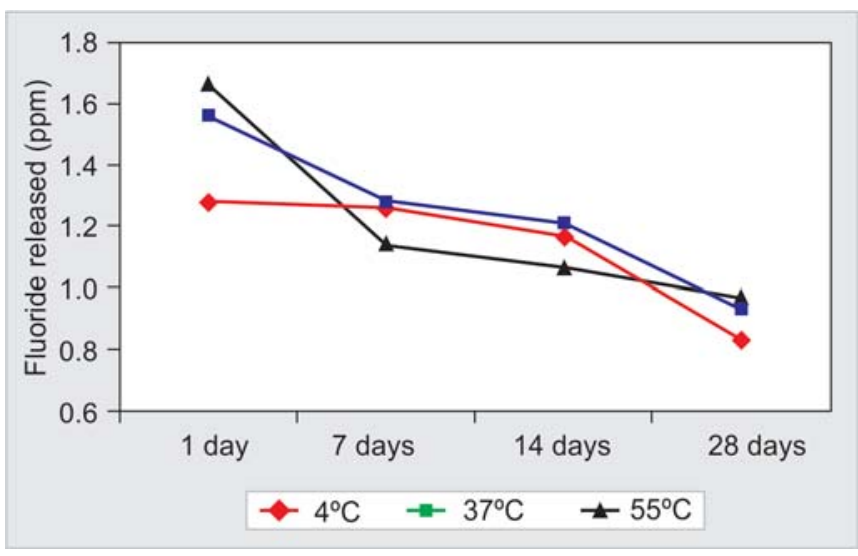

Graph 2: Effect of time interval on fluoride release in distilled water. Values are expressed as mean ppm (parts per million) $(n=6)$ was no significant ( $(\mathrm{p}>0.05)$ effect of temperature on 7 days of study $(\mathrm{F}=3.74)$. For 1 day of immersion, the amount of fluoride release was significantly high $(\mathrm{p}<0.001)$ in both $55^{\circ} \mathrm{C}$ and $37^{\circ} \mathrm{C}$ when compared to $4^{\circ} \mathrm{C}$ temperature. However, there was no significant difference between $37^{\circ} \mathrm{C}$ and $55^{\circ} \mathrm{C}$ temperature $(\mathrm{F}=92.98)$.

Effect of time interval on fluoride release in distilled water (Graph 2): At $4^{\circ} \mathrm{C}$ temperature, the amount of fluoride release was significantly high after 1 day of immersion when compared to 28 days $(\mathrm{p}<0.001)$ as well as 14 days of immersion ( $\mathrm{p}<0.01)$. It was also observed that statistically the amount of fluoride release was significantly less ( $\mathrm{p}<0.001)$ on day 28 when compared with days 14,7 and $1(\mathrm{~F}=69.241)$.

The time interval was a significant factor at $37^{\circ} \mathrm{C}$, as fluoride release was significantly $(\mathrm{p}<0.001)$ differed among all the time interval taken in the study except between days 7 and $14(\mathrm{~F}=70.181)$. However, the maximum release of fluoride was on the day of immersion.

At $55^{\circ} \mathrm{C}$ temperature, the fluoride release was significantly high $(\mathrm{p}<0.001)$ on day 1 when compared to days 7 or 14 or 21 ( $F=98.535)$.

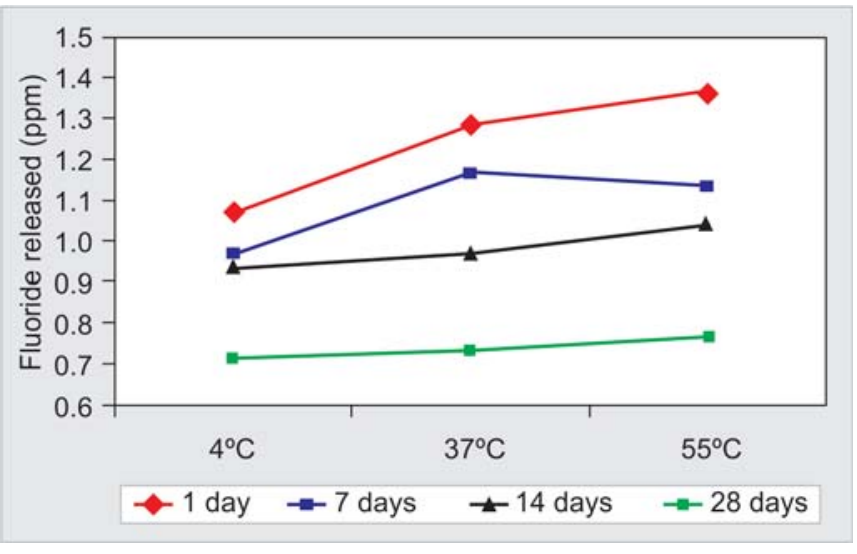

Graph 3: Effect of temperature on fluoride release in artificial saliva. Values are expressed as mean ppm (parts per million) $(n=6)$

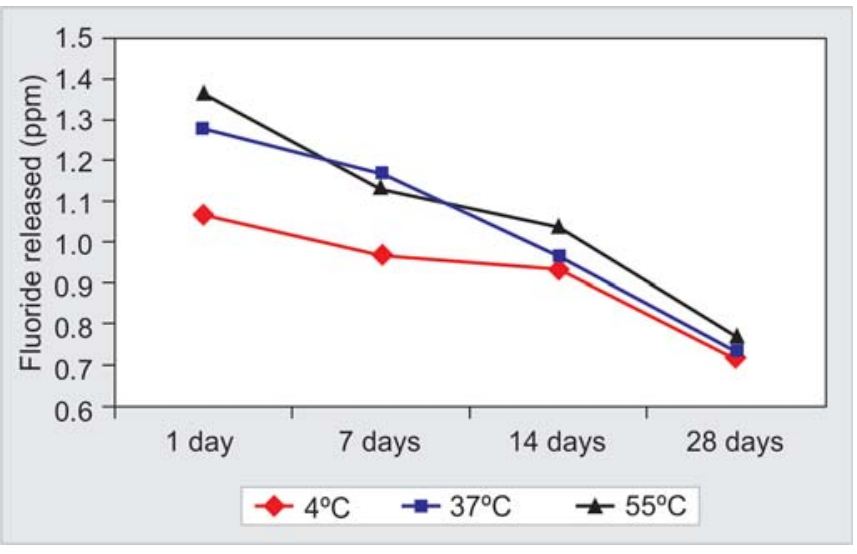

Graph 4: Effect of time interval on fluoride release in artificial saliva. Values are expressed as mean ppm (parts per million) $(n=6)$ 
Effect of temperature on fluoride release in artificial saliva (Graph 3 and Table 2): There was no temperature effect on fluoride release after 28 days of immersion ( $p>0.05$ ). There was a significant $(\mathrm{p}<0.001)$ increase in fluoride release at $55^{\circ} \mathrm{C}$ when compared to $37^{\circ} \mathrm{C}$ as well as $4^{\circ} \mathrm{C}$ temperature in 14 days of immersion period $(\mathrm{F}=25.64)$. For 7 days as well as one day of immersion study, the fluoride release was maximum at $55^{\circ} \mathrm{C}$ when compared to $37^{\circ} \mathrm{C}$ or $4^{\circ} \mathrm{C}$ temperature ( $\mathrm{p}<0.001)$. There was also a significant ( $p<0.01$ ) difference in fluoride release between $37^{\circ} \mathrm{C}$ and $55^{\circ} \mathrm{C}$ after 1 day of immersion study ( $\mathrm{F}=125.81$ for 1 day of immersion study).

Effect of time interval on fluoride release in artificial saliva (Graph 4): At $4^{\circ} \mathrm{C}$ temperature, the fluoride release was significantly high after 1 day of immersion when compared to 28 ( $\mathrm{p}<0.001$ ) days of immersion. Twenty-eight days of immersion resulted in significantly $(\mathrm{p}<0.001)$ less release of fluoride when compared to days 14 or 7 or $1(\mathrm{~F}=118.10)$. Time interval was a significant factor at $37^{\circ} \mathrm{C}$ and $55^{\circ} \mathrm{C}$, as

\begin{tabular}{|c|c|c|c|}
\hline & At $4^{\circ} \mathrm{C}$ & At $37^{\circ} \mathrm{C}$ & At $55^{\circ} \mathrm{C}$ \\
\hline 1 day & $1.285 \pm 0.004$ & $1.566 \pm 0.050$ & $1.666 \pm 0.1033$ \\
\hline 7 days & $1.26 \pm 0.08$ & $1.283 \pm 0.099$ & $1.143 \pm 0.102$ \\
\hline 14 days & $1.178 \pm 0.0733$ & $1.213 \pm 0.096$ & $1.066 \pm 0.033$ \\
\hline 28 days & $0.875 \pm 0.0233$ & $0.933 \pm 0.040$ & $0.966 \pm 0.04$ \\
\hline
\end{tabular}

\begin{tabular}{|c|c|c|c|}
\hline & At $4^{\circ} \mathrm{C}$ & At $37^{\circ} \mathrm{C}$ & At $55^{\circ} \mathrm{C}$ \\
\hline 1 day & $1.066 \pm 0.033$ & $1.283 \pm 0.021$ & $1.366 \pm 0.043$ \\
\hline 7 days & $0.966 \pm 0.0277$ & $1.166 \pm 0.033$ & $1.133 \pm 0.043$ \\
\hline 14 days & $0.933 \pm 0.023$ & $0.966 \pm 0.033$ & $1.036 \pm 0.018$ \\
\hline 28 days & $0.713 \pm 0.046$ & $0.733 \pm 0.033$ & $0.766 \pm 0.046$ \\
\hline
\end{tabular}

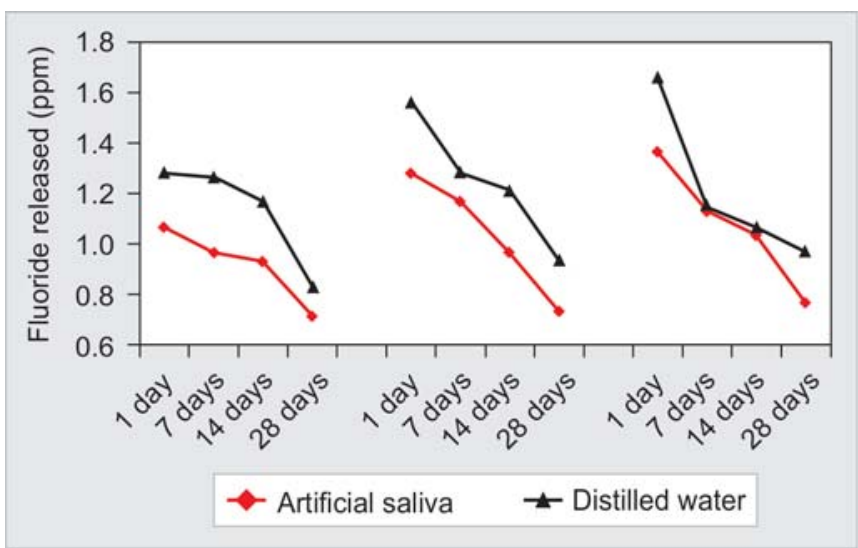

Graph 5: Comparison of fluoride release in artificial saliva and distilled water in different temperature and time interval. Values are expressed as mean ppm (parts per million) $(n=6)$ the fluoride release differed significantly at all the time intervals studied (day 1 or 7 , or 14 or 28 ) ( $\mathrm{F}=376.73$ for $37^{\circ} \mathrm{C}$ and $\mathrm{F}=241.18$ for $55^{\circ} \mathrm{C}$ temperature).

Comparison of fluoride release in artificial saliva and distilled water in different temperature and time interval (Graph 5): At $4^{\circ} \mathrm{C}$ and $37^{\circ} \mathrm{C}$ temperature, the fluoride release was significantly high in distilled water compared to artificial saliva during different time interval of studies (day 28 or 14 or 7 or 1 ). However at $55^{\circ} \mathrm{C}$ temperature, fluoride release did not differed significantly between saliva and distilled water for 7 and 14 days of immersion study.

It is also observed that the amount of fluoride release was maximum after 1 day of immersion, at $55^{\circ} \mathrm{C}$ temperature in distilled water.

To summarize, the amount of fluoride release was significantly high in distilled water when compared to artificial saliva in all the three types of GIC studied. The highest level of fluoride release was observed on the first day of the study, followed by days 7 and 14, with least release on day 28. It was also observed that at $55^{\circ} \mathrm{C}$, the amount of fluoride release was significantly high in all three GIC. However, there was no significant difference among the three GIC studied.

\section{DISCUSSION}

Most studies on fluoride release have employed deionized water as the test medium. ${ }^{10-13}$ It has been shown that the fluoride release is reduced if saliva is used as test medium. ${ }^{1,15}$ The present study also used artificial saliva to mimic the in vivo situation along with deionized water. It is apparent from the graphs that, although GIC had a relatively high fluoride release in the first day, this rapidly decreased when it reached 7, 14 and 28 days. The fact that fluoride release was greater during the first 24 hours was in agreement with studies found in literature. ${ }^{14,16}$ The reason for the rapid fall in fluoride release is likely to be because of initial burst of fluoride released from the glass particles as they dissolve in polyalkenoate acid during the setting reaction. The later slow release occurs as the glass dissolves in the water of the hydrogel matrix. ${ }^{17}$ The results for low fluoride leaching into artificial saliva may be explained because of greater viscosity of artificial saliva reduced the diffusion of water into the materials and outflow of ions. In addition, saliva may encourage the formation of surface pellicle which acts as a barrier to the process. ${ }^{18}$ These factors explain why GIC had increased fluoride release rate per hour into water whereas the release into artificial saliva decreased over the same period.

As broad temperature fluctuations occur in the oral environment, thermal circuits may frequently challenge the restorative materials placed in this environment. ${ }^{10}$ The 
present study concurred with the hypothesis that temperature had an effect on fluoride release and it varies with storage temperature. A material can only leach ions from those parts of its mass which have been penetrated by water. ${ }^{14}$ The degree of water penetration is determined by diffusion of water into materials or by surface dissolution of the matrix. Water diffusion through the material matrix derives fluoride ions to the surface, where they can be released into the storage media. ${ }^{19}$ Moreover, the diffusion behavior of the same material will change as the environmental temperature changes as explained by Atkins $\mathrm{P}$ and de Paula $\mathrm{J},{ }^{20}$ the rate constants of most processes increase as the temperature is raised. The diffusion or dissolution process is expected to be more dominant at $55^{\circ} \mathrm{C}$ when compared to $37^{\circ} \mathrm{C}$ and $4^{\circ} \mathrm{C}$ and this explains the greater fluoride release for each material under these conditions. Based on the results of this study, a higher temperature used during tropical application may increase fluoride release ability. A low oral environment temperature should be avoided during topical fluoride application.

\section{Clinical Significance}

The clinical use of GIC that release fluoride is relevant mainly in patients at risk of or with caries activity, thereby preventing initiation of secondary caries and failure of restorations. It may also be important in developing regimes for improving the delivery of tropical fluoride products. This study would be helpful to make some considerations about clinical indication and longevity of restorative materials studied.

\section{CONCLUSION}

The amount of fluoride release depends on temperature, time interval and storage condition. The result from the study concludes that GIC in the oral cavity serve as fluoride reservoir and contribute a low fluoride release in oral fluids. The clinical use of GIC that release fluoride is relevant mainly in patients at risk of or with caries activity, thereby preventing initiation of secondary caries and failure of restorations. It may also be important in developing regimes for improving the delivery of tropical fluoride products. This study would be helpful to make some considerations about clinical indication and longevity of restorative materials studied.

\section{ACKNOWLEDGMENTS}

The authors are greatful to Dr Vivian D’Souza and Dr Shalini Shenoy, Professor and Head of Biochemistry and Microbiology, Kasturba Medical College, Mangalore, for extending the equipments and lab facilities to carry out the experiment. Authors are also thankful to Dr Ishwar Bhat, Professor and Head of Chemistry, Mangalagangothri, Konaje, for permitting us to utilize the instrument and other chemicals for the study.

\section{REFERENCES}

1. Burke FM, Ray NJ, McConnell RJ. Fluoride-containing restorative materials. Int Dent J 2006 Feb;56(1):33-43.

2. Wilson NH, Burke FJ, Mjör IA. Reasons for placement and replacement of restorations of direct restorative materials by a selected group of practitioners in the United Kingdom. Quintessence Int 1997 Apr;28(4):245-248.

3. Mjör IA. The reasons for replacement and the age of failed restorations in general dental practice. Acta Odontol Scand 1997 Jan;55(1):58-63.

4. Clarkson JJ, McLoughlin J. Role of fluoride in oral health promotion. Int Dent J 2000 Jun;50(3):119-128.

5. Bratthall D, Hänsel-Petersson G, Sundberg H. Reasons for the caries decline: What do the experts believe? Eur J Oral Sci 1996 Aug;104[4 (Pt 2)]:416-442; discussion 423-425, 430-432.

6. ten Cate JM. Current concepts on the theories of the mechanism of action of fluoride. Acta Odontol Scand 1999 Dec;57(6): 325-329.

7. Griffin F, Donly K, Erickson RL. A comparison of fluoride releasing liners. American J Dent 1992;5:293-295.

8. ten Cate JM, van Duinen RN. Hypermineralization of dentinal lesions adjacent to glass-ionomer cement restorations. J Dent Res 1995 Jun;74(6):1266-1271.

9. Wiegand A, Buchalla W, Attin T. Review on fluoride-releasing restorative materials-fluoride release and uptake characteristics, antibacterial activity and influence on caries formation. Dent Mater 2007 Mar;23(3):343-362.

10. Yan Z, Sidhu SK, Mahmoud GA, Carrick TE, McCabe JF. Effects of temperature on the fluoride release and recharging ability of glass ionomers. Oper Dent 2007 Mar-Apr;32(2): 138-143.

11. Yoda A, Nikaido T, Ikeda M, Sonoda H, Foxton RM, Tagami J. Effect of curing method and storage condition on fluoride ion release from a fluoride-releasing resin cement. Dent Mater J 2006 Jun;25(2):261-266.

12. Karantakis $P$, Helvatjoglou-Antoniades M, Theodoridou-Pahini $\mathrm{S}$, Papadogiannis Y. Fluoride release from three glass ionomers, a compomer, and a composite resin in water, artificial saliva, and lactic acid. Oper Dent 2000 Jan-Feb;25(1):20-25.

13. Al-Naimi OT, Itota T, Hobson RS, McCabe JF. Fluoride release for restorative materials and its effect on biofilm formation in natural saliva. J Mater Sci Mater Med 2008 Mar;19(3): 1243-1248.

14. Preston AJ, Mair LH, Agalamanyi EA, Higham SM. Fluoride release from aesthetic dental materials. J Oral Rehabil 1999 Feb;26(2):123-129.

15. Damen JJ, Buijs MJ, ten Cate JM. Uptake and release of fluoride by saliva-coated glass ionomer cement. Caries Res 1996;30(6): 454-457.

16. Diaz-Arnold AM, Holmes DC, Wistrom DW, Swift EJ Jr. Shortterm fluoride release/uptake of glass ionomer restoratives. Dent Mater 1995 Mar;11(2):96-101.

17. De Moor RJ, Verbeeck RM, De Maeyer EA. Fluoride release profiles of restorative glass ionomer formulations. Dent Mater 1996 Mar;12(2):88-95. 
18. Lenander-Lumikari M, Loimaranta V. Saliva and dental caries. Adv Dent Res 2000 Dec;14:40-47.

19. Tay WM, Braden M. Fluoride ion diffusion from polyalkenoate (glass-ionomer) cements. Biomaterials 1988 Sep; 9(5):454-456.

20. Atkins P, de Paula J. Atkin's physical chemistry. Oxford University Express: England, 2002;24.

\section{ABOUT THE AUTHORS}

\section{Prashanthi Madhyastha (Corresponding Author)}

Senior Grade Lecturer, Department of Dental Materials, Manipal College of Dental Sciences, Manipal University, Mangalore Karnataka, India, e-mail: prashanthismadhyast@yahoo.co.in

\section{Ravindra Kotian}

Reader and Head, Department of Dental Materials, Manipal College of Dental Sciences, Manipal University, Mangalore Karnataka, India

\section{Vivekananda Pai}

Professor and Head, Department of Conservative Dentistry, Manipal College of Dental Sciences, Manipal University, Mangalore Karnataka, India

\section{AMA Khader}

Professor, Department of Chemistry, Mangalore University Mangalore, Karnataka, India 